\title{
Genetic influences on the insulin response of the beta cell to different secretagogues
}

\author{
A. M. C. Simonis-Bik • E. M. W. Eekhoff • M. H. M. de Moor • M. H. H. Kramer • \\ D. I. Boomsma • R. J. Heine • J. M. Dekker • J. A. Maassen • L. M. 't Hart • \\ M. Diamant • E. J. C. de Geus
}

Received: 23 June 2009/Accepted: 20 August 2009/Published online: 3 October 2009

(C) Springer-Verlag 2009

\begin{abstract}
Aims/hypothesis The aim of the present study was to estimate the heritability of the beta cell insulin response to glucose and to glucose combined with glucagon-like peptide-1 (GLP-1) or with GLP-1 plus arginine.

Methods This was a twin-family study that included 54 families from the Netherlands Twin Register. The participants were healthy twin pairs and their siblings of the same sex, aged 20 to 50 years. Insulin response of the beta cell was assessed by a modified hyperglycaemic clamp with additional GLP-1 and arginine. Insulin sensitivity index (ISI) was assessed by the euglycaemic-hyperinsulinaemic
\end{abstract}

Electronic supplementary material The online version of this article (doi:10.1007/s00125-009-1532-3) contains supplementary material, which is available to authorized users.

A. M. C. Simonis-Bik $(\bowtie) \cdot$ E. M. W. Eekhoff $\cdot$ R. J. Heine

J. A. Maassen $\cdot$ M. Diamant

Diabetes Centre, VU University Medical Centre,

ZH 4A62, PO Box 7057, 1007 Amsterdam, the Netherlands

e-mail: amc.simonis-bik@vumc.nl

M. H. M. de Moor • D. I. Boomsma • E. J. C. de Geus

Biological Psychology, VU University,

Amsterdam, the Netherlands

\section{H. H. Kramer}

Internal Medicine, VU University Medical Centre,

Amsterdam, the Netherlands

\section{R. J. Heine $\cdot$ J. M. Dekker}

EMGO Institute for Health and Care Research,

VU University Medical Centre,

Amsterdam, the Netherlands

L. M. 't Hart

Molecular Cell Biology, Leiden University Medical Centre,

Leiden, the Netherlands clamp. Multivariate structural equation modelling was used to obtain heritabilities and the genetic factors underlying individual differences in BMI, ISI and secretory responses of the beta cell.

Results The heritability of insulin levels in response to glucose was $52 \%$ and $77 \%$ for the first and second phase, respectively, $53 \%$ in response to glucose+GLP-1 and $80 \%$ in response to an additional arginine bolus. Insulin responses to the administration of glucose, glucose + GLP-1 and glucose + GLP-1+arginine were highly correlated $(0.62<r<0.79)$. Heritability of BMI and ISI was $74 \%$ and $60 \%$ respectively. The genetic factors that influenced BMI and ISI explained about half of the heritability of insulin levels in response to the three secretagogues. The other half was due to genetic factors specific to the beta cell.

Conclusions/interpretation In healthy adults, genetic factors explain most of the individual differences in the secretory capacity of the beta cell. These genetic influences are partly independent from the genes that influence BMI and ISI.

Keywords Arginine - Beta cell · Genes · GLP-1 · Heritability · Hyperglycaemic clamp · Insulin sensitivity · Twin

$\begin{array}{ll}\text { Abbreviations } \\ \text { A } & \text { Additive genetic variance } \\ \text { ARG-IR } & \text { Arginine-induced insulin response } \\ \text { C } & \begin{array}{l}\text { Common environmental variance shared by } \\ \text { family members }\end{array} \\ \text { E } & \text { Unique environmental variance } \\ \text { GLP-1IR } & \text { GLP-1 stimulated insulin response } \\ \text { GLP-1 } & \text { Glucagon-like peptide-1 } \\ \text { GWA } & \text { Genome-wide association } \\ \text { ISI } & \text { Insulin sensitivity index }\end{array}$




\section{Introduction}

Type 2 diabetes mellitus is a multifactorial disease, characterised by decreased insulin sensitivity and inadequate insulin secretion by the pancreatic beta cell [1]. Twin [2-5] and family studies [6-10] support the notion that people who develop type 2 diabetes have a strong genetic predisposition, which may be partly conveyed through genetic effects on insulin resistance. Two twin studies, for instance, showed a significant genetic contribution to insulin sensitivity, assessed by euglycaemic-hyperinsulinaemic clamp with heritability estimates of $37 \%$ and $55 \%$ $[11,12]$. Notwithstanding the importance of insulin sensitivity, genetic effects on beta cell function are likely to play a major role in the development of type 2 diabetes. Thus many of the genetic variants in and near genes recently found to be associated with risk of type 2 diabetes [13] influence beta cell function [14]. In twin studies, the genetic contribution to beta cell function has been tested mostly by examining surrogate measurements of insulin secretion derived from fasting blood levels or in response to oral glucose. In five studies using IVGTT, heritability estimates of the acute insulin response to glucose ranged from $35 \%$ to $76 \%[6,11,15-17]$. The heritability of the second-phase insulin response to glucose in an IVGTT has been investigated in two of these studies only $[11,17]$ and was estimated to be $28 \%$ and $58 \%$.

Glucose is the key regulator of insulin secretion by the beta cell, which occurs through activation of the glycolytic flux, followed by mitochondrial activation, membrane depolarisation and finally release of insulin. However, under typical physiological conditions various non-glucose secretagogues also affect insulin secretion. These include incretins like glucagon-like petide-1 (GLP-1), which is immediately secreted by the gut in reaction to a meal [18] and causes G-protein-coupled receptor activation of adenylate cyclase, and amino acids like arginine, which depolarises the beta cell membrane [19]. Abnormal insulin responses after administration of these secretagogues may be a first sign of development of type 2 diabetes mellitus [20]. To date, no studies have estimated the heritability of insulin response to glucose combined with GLP-1 and arginine. Furthermore, it is unclear whether the secretory responses to glucose+GLP-1 and glucose+GLP-1+arginine are governed by the same genetic factors as the response to glucose alone. Although there is overlap in the mechanism by which they stimulate insulin secretion, each of these secretagogues also has a specific intracellular pathway that may be influenced by different sets of genes $[18,19]$.

Increased understanding of the genetics of the different aspects of beta cell function and dysfunction may identify new targets for glucose-lowering drugs or preventive measures. The aim of this twin-family study was to explore the heritability of beta cell insulin response by using a modified hyperglycaemic clamp based on the procedure by Fritsche and colleagues [21]. Apart from estimating the heritability of insulin response to glucose (first and second phase), GLP-1 and arginine, we also tested whether different genetic factors influence insulin response to each of these three secretagogues. Since the insulin response is strongly correlated to BMI and insulin sensitivity [22, 23], measures of BMI and insulin sensitivity were assessed on the same day, the latter by the euglycaemic-hyperinsulinaemic clamp. This allowed us to test to which extent genetic factors influencing insulin response overlap with those influencing BMI and insulin sensitivity.

\section{Methods}

Design and participants This study used a twin/same-sex sibling design to address the genetic and environmental contribution to the variance of beta cell function in Dutch twin families recruited from the Netherlands Twin Register [24] as described previously [25]. The clamp tests were performed in 125 (58 men) healthy participants, aged 20 to 50 years and of European origin. In the weeks prior to these clamp tests, participants had been assessed with a $75 \mathrm{~g}$ screening OGTT to exclude the presence of diabetes mellitus. There were 34 monozygotic twin pairs and 13 same-sex dizygotic twin pairs from 47 families. Eight monozygotic twin pairs and five dizygotic twin pairs had one additional same-sex sibling. Two monozygotic twin pairs had two additional same-sex siblings. In six more families only one twin of the pair participated, together with a same-sex sibling. In one family no twin pair but two female siblings took part in the study. In total, 100 twins and 25 siblings participated. Twin zygosity was determined from DNA polymorphisms. In total 44 dizygotic/sibling pairs could be formed. The median age difference between twins and sibs was 3.5 years with a range of 1.8 to 9.1 years. Including an additional sibling in the classical twin design significantly increases the power to detect the genetic and environmental sources of variation [26].

All participants gave written informed consent. The study was approved by the local Ethics Committee and performed in accordance with the Declaration of Helsinki.

Euglycaemic-hyperinsulinaemic clamp After a $12 \mathrm{~h}$ fast the clamp procedure [27] started in the clinic at 08:00 hours. Anthropometric measurements of weight (Seca balance scale; Schinkel, Nieuwegein, the Netherlands), height (Harpenden Stadiometer; Holtain, Crosswell, UK) and waist and hip circumference [28] were performed. One cannula was retrogradely placed in a heated dorsal hand 
vein to obtain arterialised blood. A second cannula was inserted into the antecubital vein of the arm for infusion of $0.9 \%$ saline (wt/vol.), glucose $20 \%$ (wt/vol.) and insulin. After baseline samples had been taken twice, a primed, continuous $\left(40 \mathrm{mU} \mathrm{m} \mathrm{min}^{-1}\right)$ insulin infusion (Actrapid; Novo Nordisk, Bagsvaer, Denmark) was given for $120 \mathrm{~min}$. Glucose $20 \%$ was infused at a variable rate to maintain blood glucose at $0.3 \mathrm{mmol} / 1$ below the fasting level and within the range of 4.5 to $5.5 \mathrm{mmol} / \mathrm{l}$. Blood glucose was monitored at $5 \mathrm{~min}$ intervals; blood samples for hormonal levels were obtained at 60, 90, 105 and $120 \mathrm{~min}$.

Modified hyperglycaemic clamp At $1 \mathrm{~h}$ after completion of the euglycaemic-hyperinsulinaemic clamp, the hyperglycaemic clamp was performed at $10 \mathrm{mmol} / \mathrm{l}$ as described by Fritsche et al. [21]. The blood glucose level was frequently monitored (at least every $5 \mathrm{~min}$ ) and the infusion rate of glucose $20 \%$ accordingly adjusted. Blood samples for measurement of insulin and C-peptide were drawn at fixed time points, i.e. (1) at -5 and -2 min before the start of the hyperglycaemic clamp; (2) every min for $10 \mathrm{~min}$ after a bolus of each secretagogue; and (3) at 5 to 30 min intervals in the periods in-between. At $0 \mathrm{~min}$ the participant received an intravenous bolus of glucose for 1 min to acutely raise glucose level to $10 \mathrm{mmol} / \mathrm{l}$ (bolus calculated as follows: weight in $\mathrm{kg} \times[10-$ prehyperglycaemic glucose level in $\mathrm{mmol} / 1] \times 27 / 200=\mathrm{ml}$ glucose $20 \%$ ). At $120 \mathrm{~min}$ (i.e. $2 \mathrm{~h}$ later) GLP-1 (7-36 Amide Human; Polypeptide Laboratories, Wolfenbuettel, Germany) was given as a bolus injection $(1.5 \mathrm{pmol} / \mathrm{kg})$ for $1 \mathrm{~min}$, followed by continuous infusion of $0.5 \mathrm{pmol} \mathrm{kg}^{-1} \mathrm{~min}^{-1}$. At $180 \mathrm{~min}$, a bolus of $5 \mathrm{~g}$ arginine was injected over $50 \mathrm{~s}$ on top of the GLP-1 infusion. The GLP-1 infusion was terminated 20 min after the arginine bolus and the clamp finished.

Analytical procedures Blood glucose was assessed at bedside using a glucose oxidase method (YSI 2300 Stat plus; Yellow Springs Instruments, Yellow Springs, OH, USA). This device has a within-run CV of $2 \%$ and a day-today $\mathrm{CV}$ of $6 \%$ [29]. Blood for hormonal levels was centrifuged $(1,469 \mathrm{~g})$ and the serum stored at $-80^{\circ} \mathrm{C}$. All serum specimens were assessed for insulin and C-peptide levels at the VU University Medical Centre (Department of Clinical Chemistry, Amsterdam, the Netherlands) using an immunometric assay luminescence method (ACS:Centaur; Bayer Diagnostics, Mijdrecht, the Netherlands). There was no cross-reactivity with proinsulin or split products. The inter assay CV of insulin and C-peptide measurement was $6.5 \%$ and $6 \%$ respectively. The intra-assay $\mathrm{CV}$ was $4 \%$ for both.

Calculations BMI was calculated as weight in $\mathrm{kg} /$ (height in metres) ${ }^{2}$. The insulin sensitivity index (ISI) was defined as the glucose infusion rate per $\mathrm{kg}$ of body weight during the second $\mathrm{h}$ of the euglycaemic-hyperinsulinaemic clamp per unit of serum insulin concentration $\left(\mu \mathrm{mol} \mathrm{kg} \mathrm{kg}^{-1} \mathrm{~min}^{-1}\right.$ $\left(\mathrm{pmol} / \mathrm{l}^{-1}\right)$. The incremental insulin response to the secretagogues was calculated in four periods named firstphase, second-phase, GLP-1-stimulated insulin response (GLP-1IR) and arginine-induced insulin response (ARGIR), using the AUCs of the measured insulin levels as depicted in Fig. 1. The first phase comprised the acute response to hyperglycaemia and was computed as the AUC of the insulin level during min 1 to 10 , using the mean baseline level from -5 to $-2 \mathrm{~min}$. The second phase comprised the AUC from 80 to 120 min, again using the mean from -5 to $-2 \mathrm{~min}$ as the baseline level. The GLP1IR was calculated as the AUC from 160 to 180 min, using the last period of the second phase from 100 to $120 \mathrm{~min}$ as the baseline. The acute ARG-IR was calculated as the AUC from 182 to $185 \mathrm{~min}$ minus the prebolus level (at $180 \mathrm{~min}$ ). C-peptide responses to the three secretagogues were calculated in the same way.

Statistical analyses All genetic analyses were carried out in Mx [30], a structural equation modelling program specifically designed for the analysis of twin and family data. All variables (BMI, ISI, first-phase, second-phase, GLP-1IR and ARG-IR) were $Z$ transformed prior to analysis (mean $=0$, $\mathrm{SD}=1$ ) to reduce the large differences in variances across the variables. This transformation does not affect the estimates of familial correlations or of heritabilities.

In a first step, we confirmed that the variances of the variables were comparable for twins and siblings and that the covariances between dizygotic twins could be equated to those between a twin and a singleton sibling. The latter allowed us to treat all sibling pairs sharing $50 \%$ of their genetic material, whether dizygotic twin or twin-sibling pair, in the same way. Next we estimated correlations

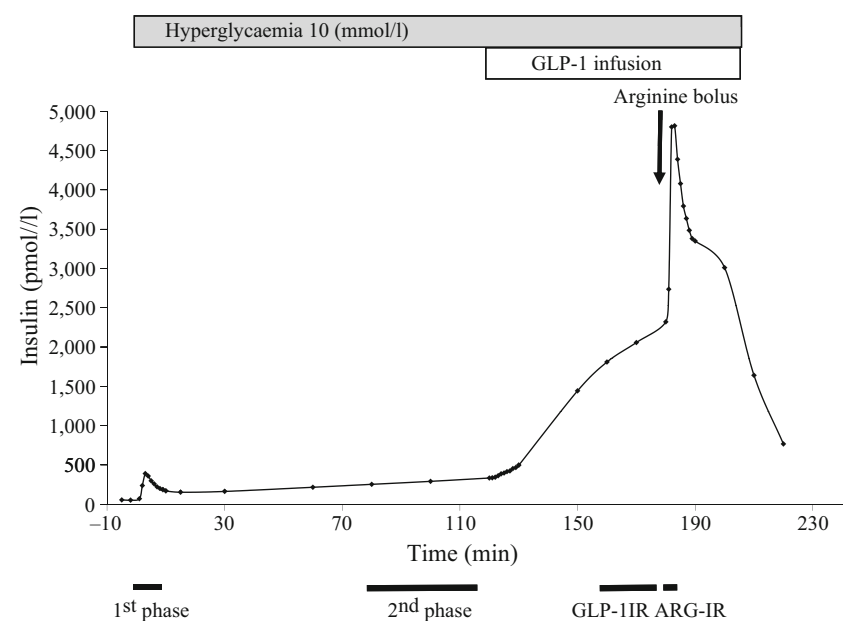

Fig. 1 Insulin levels during the hyperglycaemic clamp. The curve indicates the incremental insulin response to the different secretagogues 
among family members and among variables in a model that included the fixed effects of sex and age on each variable. Broadly, we can distinguish between three types of correlations: cross-variable within-person correlations (phenotypic correlations), within-variable cross-person correlations (familial correlations, i.e. monozygotic and dizygotic/sibling correlations) and cross-variable cross-person correlations. The phenotypic correlations describe the correlations among the four secretory responses (firstphase, second-phase, GLP-1IR and ARG-IR), BMI and insulin sensitivity. The monozygotic and dizygotic/sibling correlations describe the resemblance for these variables in monozygotic twins and in all other pairs of first-degree relatives (dizygotic twins, twin-sibling, sibling-sibling). These correlations form the basis for estimating the relative contributions of genetic and environmental factors to individual differences in each variable. Monozygotic twin pairs have all or nearly all genes in common; dizygotic twin pairs, twin-sibling pairs and sibling-sibling pairs share on average half of their segregating genes. If monozygotic correlations are larger than the dizygotic/sibling correlations, genetic influences are suggested.

Monozygotic and dizygotic/sibling correlations can also be computed across variables (cross-variable cross-person correlations), for example between the first-phase secretory response of a twin and the second-phase secretory response of his or her co-twin. When the cross-variable cross-person correlation is larger in monozygotic twin than in dizygotic/ sibling pairs, this indicates that part of the association between variables is explained by overlapping genetic factors.
Next, a multivariate genetic model [31] was fitted to the data. For each of the six variables in the model, the total variance was broken down into additive genetic variance (A), common environmental variance shared by family members $(\mathrm{C})$ and unique environmental variance $(\mathrm{E})$. The full multivariate model included a set of six factors for A, C and $\mathrm{E}$ (Electronic supplementary material [ESM] Fig. 1). The first factor influences all six variables; the next factor influences five variables and the last factor only one variable. We tested whether the contributions of these A and $\mathrm{C}$ factors were all significant using likelihood-ratio tests. The difference in minus two times the log-likelihood $(-2 \mathrm{LL})$ between two nested models has a $\chi^{2}$ distribution. A corresponding $p$ value $>0.05$ indicated that the more parsimonious model did not fit the data less well than the full model. Next the paths of each A and E factor to the six variables were tested for significance. This procedure was repeated to arrive at the most parsimonious model that fitted the data. Under this model, we estimated the heritability of each variable individually and broke this heritability down into: (1) components that overlap with BMI and ISI; (2) components that are specific to insulin response but shared among secretagogues; and (3) components that are specific to each secretagogue.

\section{Results}

Sample characteristics are shown in Table 1 and the insulin levels attained during the hyperglycaemic clamp and GLP-1

Table 1 Sample characteristics

\begin{tabular}{|c|c|c|c|c|c|c|}
\hline Variable & Mean total & SD & Mean male & $\mathrm{SD}$ & Mean female & SD \\
\hline Number & 125 & & 58 & & 67 & \\
\hline Age (years) & 30.8 & 5.6 & 30.4 & 5.2 & 31.2 & 5.9 \\
\hline Waist (cm) & 85.5 & 10.2 & $88.2 * *$ & 9.7 & 83.2 & 10.2 \\
\hline Weight (kg) & 74.2 & 12.0 & $80.5^{* *}$ & 10.4 & 68.8 & 10.5 \\
\hline BMI $\left(\mathrm{kg} / \mathrm{m}^{2}\right)$ & 24.0 & 3.4 & 24.1 & 3.0 & 23.96 & 3.8 \\
\hline ISI $\left(\mu \mathrm{mol} \min ^{-1} \mathrm{~kg}^{-1}[\mathrm{pmol} / 1]^{-1}\right)$ & 0.091 & 0.039 & 0.098 & 0.047 & 0.084 & 0.029 \\
\hline \multicolumn{7}{|l|}{ Insulin response $(\mathrm{pmolxmin} / \mathrm{l})^{\mathrm{a}}$} \\
\hline First-phase & 1,700 & 1,114 & $1,942^{*}$ & 1,247 & 1,484 & 938 \\
\hline Second-phase & 9,337 & 7,471 & $10,830^{*}$ & 8,566 & 8,043 & 6,153 \\
\hline GLP-1 & 34,498 & 30,433 & $49,448 * *$ & 35,333 & 21,361 & 16,829 \\
\hline Arginine & 6,602 & 3,037 & $7,758 * *$ & 3,147 & 5,554 & 2,533 \\
\hline \multicolumn{7}{|l|}{ C-peptide response $(\mathrm{nmolxmin} / \mathrm{l})^{\mathrm{a}}$} \\
\hline First-phase & 5.713 & 3.030 & $6.649 * *$ & 3.383 & 4.878 & 2.409 \\
\hline Second-phase & 66.68 & 26.65 & $74.74 * *$ & 29.16 & 59.70 & 22.21 \\
\hline GLP-1 & 72.63 & 35.49 & $93.15^{* *}$ & 36.05 & 54.60 & 23.20 \\
\hline Arginine & 7.913 & 2.908 & 8.332 & 3.240 & 7.534 & 2.538 \\
\hline
\end{tabular}

${ }^{a}$ Responses during the hyperglycaemic clamp are given as incremental responses, as defined in "Methods"

${ }^{*} p<0.05,{ }^{* *} p<0.01$ vs female 
and arginine additions in Fig. 1. The mean insulin secretion in response to the secretagogues was larger in men. This difference was highly significant after stimulation with GLP-1 $\left(\chi^{2}=18.44, \Delta \mathrm{df}=1, \quad p<0.001\right)$ and arginine $\left(\chi^{2}=9.89\right.$, $\Delta \mathrm{df}=1, p=0.002)$. The mean waist circumference was significantly larger in men $\left(\chi^{2}=7.05, \Delta \mathrm{df}=1, p=0.01\right)$. There was no significant influence of age on the means of BMI, ISI and the four secretory responses $\left(\chi^{2}=11.03, \Delta \mathrm{df}=6\right.$, $p=0.09$ ).

Phenotypic correlations are given in Table 2 and were all significantly larger than zero. The insulin secretion in response to glucose (first and second phase), glucose+ GLP-1 and glucose + GLP-1 + arginine was highly correlated $(0.62<r<0.79)$.

Within-variable cross-person correlations are presented in Table 3. Monozygotic twin correlations were all larger than dizygotic twin/sibling correlations. This indicates that genetic factors play a role in the variability of BMI, insulin sensitivity and insulin secretion after intravenous administration of glucose, glucose + GLP-1 and glucose + GLP- $1+$ arginine.

Cross-variable cross-person correlations are shown in Table 4. Monozygotic cross-twin cross-variable correlations were all larger than the dizygotic twin/sibling cross-variable correlations. These correlations indicate that overlapping genes contribute to the phenotypic correlations between BMI, insulin sensitivity and the insulin response to the different secretagogues.

In the full multivariate genetic ACE model, the contribution of A (combination of all additive genetic factors) proved to be significant $\left(\chi^{2}=48.77, \Delta \mathrm{df}=21, p=0.001\right)$, while $\mathrm{C}$ (combination of all common environmental factors) could be dropped from the model $\left(\chi^{2}=4.77, \Delta \mathrm{df}=21\right.$, $p=1.00$ ). Further testing showed that in the resulting $\mathrm{AE}$ model, four single A paths and four single E paths could be constrained to zero $\left(\chi^{2}=6.64, \Delta \mathrm{df}=8, p=0.58\right)$. The most parsimonious AE model with path loadings is presented in ESM Fig. 2.

In this best-fitting model there are two sets of genetic factors that influence the insulin response to the four stimulations independently of BMI and ISI. The genetic factors that influence BMI and ISI also influence the variability of the four secretory responses. The heritability estimates of the six variables are presented in Table 5. The heritability of BMI is estimated at $74 \%$. The heritability of insulin sensitivity is $60 \%$. Part of the genes influencing BMI also influence ISI. The first-phase response has a heritability of $52 \%$, of which a small part $(14 \%)$ is due to genetic factors specific for the insulin response and independent of the genetic factors for BMI and ISI heritability. The second-phase response has a heritability of $77 \%$, of which nearly half can be attributed to the genes specific for the insulin response. The heritability of insulin secretion in response to GLP-1 was $53 \%$, mainly determined by genes specific for the insulin response. The secretory response to arginine had a heritability of $80 \%$, of which $44 \%$ reflects genetic overlap with BMI and ISI, while $36 \%$ is specific for the insulin response. The maximum insulin level during the test was generated directly after the arginine bolus. The heritability of this total peak level was $77 \%$.

Three alternative analyses were performed to bolster our confidence in these results (data not shown). First, correlations in Tables 2, 3, 4 and 5 were recomputed using C-peptide instead of insulin. This yielded virtually identical results. Second, we used the total AUC with zero as a baseline for the GLP-1 and arginine phases, rather than the incremental AUC with the previous levels as a baseline. As expected from the high correlation between absolute and incremental GLP-1 $(r=0.99)$ and arginine $(r=0.91)$ responses, highly similar patterns of twin sibling correlations were obtained when using the total AUCs. Finally, because waist circumference is seen by some researchers as more discriminating for the risk of type 2 diabetes [32], we repeated the analyses replacing BMI by waist. The heritability for waist circumference was $75 \%$, its correlation to BMI $r=0.84$. Again highly comparable patterns of twin sibling correlations were obtained when using waist circumference instead of BMI.

\section{Discussion}

This study used a twin/sibling design to explore heritability of the insulin response of the beta cell in healthy

Table 2 Phenotypic correlations (95\% CI) between BMI, insulin sensitivity and the insulin responses of the beta cell

\begin{tabular}{|c|c|c|c|c|c|}
\hline Variable & BMI & ISI & First-phase & Second-phase & GLP-1IR \\
\hline ISI & $-0.45(-0.60,-0.24)$ & & & & \\
\hline First-phase & $0.42(0.23,0.58)$ & $-0.56(-0.69,-0.40)$ & & & \\
\hline Second-phase & $0.48(0.30,0.63)$ & $-0.57(-0.69,-0.41)$ & $0.79(0.71,0.86)$ & & \\
\hline GLP-1IR & $0.46(0.27,0.61)$ & $-0.56(-0.69,-0.41)$ & $0.67(0.54,0.76)$ & $0.79(0.71,0.86)$ & \\
\hline ARG-IR & $0.44(0.26,0.59)$ & $-0.55(-0.68,-0.39)$ & $0.62(0.48,0.73)$ & $0.67(0.54,0.77)$ & $0.70(0.61,0.80)$ \\
\hline
\end{tabular}


Table 3 Within-variable cross-person correlations (95\% CI) for monozygotic twin and dizygotic twin/sibling pairs

\begin{tabular}{lll}
\hline Variable & $\begin{array}{l}\text { Monozygotic } \\
\text { twin pairs }\end{array}$ & $\begin{array}{l}\text { Dizygotic twin/ } \\
\text { sibling pairs }\end{array}$ \\
\hline BMI & $0.75(0.57,0.83)$ & $0.44(0.17,0.65)$ \\
ISI & $0.76(0.53,0.87)$ & $0.12(-0.15,0.38)$ \\
First-phase & $0.63(0.38,0.78)$ & $0.22(-0.16,0.51)$ \\
Second-phase & $0.76(0.61,0.86)$ & $0.31(-0.12,0.60)$ \\
GLP-1IR & $0.57(0.33,0.74)$ & $0.37(-0.00,0.67)$ \\
ARG-IR & $0.82(0.68,0.89)$ & $0.22(-0.11,0.50)$ \\
\hline
\end{tabular}

individuals during a modified version of the hyperglycaemic clamp test used by Fritsche and colleagues [21]. The heritability of first- and second-phase insulin secretion in response to glucose was $52 \%$ and $77 \%$ respectively. For the first phase our results fit neatly in the $35 \%$ to $76 \%$ range of heritability estimates previously reported using the IVGTT test $[6,11,15-17]$. However, previous heritability estimates $(28 \%$ and $58 \%)$ of second-phase insulin secretion in response to IVGTT were considerably lower $[11,17]$ than those found in our hyperglycaemic clamp. This may reflect the greater precision inherent in the clamp method in comparison to the IVGTT, but may also be due to the different stimulation of the beta cell during the second phase of both tests (maintaining $10 \mathrm{mmol} / \mathrm{l}$ glucose vs decreasing glucose level).

Insulin secretion in response to administration of GLP-1 or GLP-1+arginine in the presence of hyperglycaemia has been tentatively suggested as an endophenotype for type 2 diabetes mellitus risk [20]. Here we show for the first time that these secretory responses do indeed show significant heritability (GLP-1 53\%, arginine 80\%). Moreover, the genetic information contained in the insulin response to these two secretagogues is only partially captured by the first-phase insulin response during the hyperglycaemic clamp. The multivariate analysis of the insulin responses to the three secretagogues and BMI and ISI showed that the genetic variance unique to beta cell function (factors A3+A4) contributed less strongly to individual differences in the first-phase response (14\%) than in the second-phase response or in the responses to GLP-1 and GLP-1+arginine (30-37\%).

Overall, the findings clearly show that the genetic variation in beta cell function is only partly attributable to genes influencing BMI and ISI. These findings cannot simply be attributed to a restricted range of BMI or ISI values in this healthy sample, since our heritability estimates of BMI and insulin sensitivity are very comparable to previous estimates [11, 12, 33]. Furthermore, the partial independence of genetic factors influencing beta cell function from those influencing BMI is congruent with the outcome of previous genome-wide association (GWA) studies addressing the genetic risk of diabetes. These show that correction for BMI can sometimes reduce the significance of SNP associations with type 2 diabetes, with the FTO gene being the most prominent example [34]. This suggests that obesity genes like FTO may belong to the first genetic factor (A1) in ESM Fig. 2. This raises the question of whether correction for BMI is appropriate if the goal is to identify genes 'that influence diabetes risk'. Part of the genetic risk for insulin sensitivity and beta cell function truly overlaps with the risk for obesity.

The partial independence of the genetic factors influencing the beta cell response from those influencing insulin sensitivity is also congruent with the outcome of previous GWA studies and the follow-up of their major candidate genes in experimental studies. The majority of the $\sim 20$ loci shown in GWA studies to be associated with type 2 diabetes or fasting glucose are almost all implicated in

Table 4 Cross-variable cross-person correlations (95\% CI), with monozygotic twin-pairs in lower diagonal and dizygotic twin/sibling pairs in upper diagonal

\begin{tabular}{|c|c|c|c|c|c|c|}
\hline Variable & BMI & ISI & First-phase & Second-phase & GLP-1IR & ARG-IR \\
\hline BMI & & $\begin{array}{c}-0.10 \\
(-0.32,0.12)\end{array}$ & $\begin{array}{c}0.10 \\
(-0.16,0.33)\end{array}$ & $\begin{array}{c}0.17 \\
(-0.11,0.40)\end{array}$ & $\begin{array}{c}0.17 \\
(-0.10,0.40)\end{array}$ & $\begin{array}{c}0.19 \\
(-0.06,0.41)\end{array}$ \\
\hline ISI & $\begin{array}{c}-0.33 \\
(-0.51,-0.18)\end{array}$ & & $\begin{array}{c}-0.25 \\
(-0.46,-0.00)\end{array}$ & $\begin{array}{c}-0.28 \\
(-0.49,-0.02)\end{array}$ & $\begin{array}{c}-0.20 \\
(-0.42,0.05)\end{array}$ & $\begin{array}{c}-0.13 \\
(-0.36,0.11)\end{array}$ \\
\hline First-phase & $\begin{array}{c}0.31 \\
(0.09,0.50)\end{array}$ & $\begin{array}{c}-0.43 \\
(-0.60,-0.21)\end{array}$ & & $\begin{array}{c}0.27 \\
(-0.12,0.53)\end{array}$ & $\begin{array}{c}0.24 \\
(-0.11,0.48)\end{array}$ & $\begin{array}{c}0.14 \\
(-0.17,0.40)\end{array}$ \\
\hline Second-phase & $\begin{array}{c}0.33 \\
(0.13,0.51)\end{array}$ & $\begin{array}{c}-0.45 \\
(-0.61,-0.26)\end{array}$ & $\begin{array}{c}0.60 \\
(0.42,0.72)\end{array}$ & & $\begin{array}{c}0.33 \\
(-0.04,0.59)\end{array}$ & $\begin{array}{c}0.19 \\
(-0.15,0.45)\end{array}$ \\
\hline GLP-1IR & $\begin{array}{c}0.25 \\
(0.03,0.45)\end{array}$ & $\begin{array}{c}-0.37 \\
(-0.55,-0.14)\end{array}$ & $\begin{array}{c}0.46 \\
(0.25,0.62)\end{array}$ & $\begin{array}{c}0.56 \\
(0.38,0.70)\end{array}$ & & $\begin{array}{c}0.24 \\
(-0.09,0.49)\end{array}$ \\
\hline ARG-IR & $\begin{array}{c}0.34 \\
(0.14,0.51)\end{array}$ & $\begin{array}{c}-0.46 \\
(-0.61,-0.27)\end{array}$ & $\begin{array}{c}0.46 \\
(0.26,0.61)\end{array}$ & $\begin{array}{c}0.56 \\
(0.40,0.69)\end{array}$ & $\begin{array}{c}0.52 \\
(0.34,0.66)\end{array}$ & \\
\hline
\end{tabular}


Table 5 Heritability of BMI, ISI and the insulin responses of the beta cell

\begin{tabular}{lllll}
\hline Variable & \multicolumn{4}{l}{ Heritability } \\
\cline { 2 - 5 } & $\begin{array}{l}\text { Total } \\
\text { heritability }\end{array}$ & $\begin{array}{l}\text { Overlap } \\
\text { with BMI }\end{array}$ & $\begin{array}{l}\text { Overlap } \\
\text { with ISI }\end{array}$ & $\begin{array}{l}\text { Overlap with } \\
\text { insulin secretion }\end{array}$ \\
\hline BMI & $74(56,85)$ & 74 & & \\
ISI & $60(32,80)$ & 14 & 46 & \\
First-phase & $52(29,70)$ & 12 & 26 & 14 \\
Second-phase & $77(60,86)$ & 18 & 29 & 30 \\
GLP-1IR & $53(33,70)$ & 7 & 9 & 37 \\
ARG-IR & $80(65,88)$ & 14 & 30 & 36 \\
\hline
\end{tabular}

Values are per cent $(95 \% \mathrm{CI})$

defective beta cell function [14, 35]. Almost none of these genes were found to affect peripheral insulin sensitivity. Most notably, all previous studies that used a hyperglycaemic clamp procedure comparable to the one used here confirm the independence of genetic effects on insulin secretion and insulin sensitivity. For instance, the risk variants of CDKAL1, IGF2BP2 [36], TCF7L2 [37] or WFS1 [38] clearly impaired glucose- or GLP-1-induced insulin secretion, but did not impact on insulin sensitivity.

It has often been suggested that beta cell dysfunction is uncovered only when insulin resistance creates a strongly increased insulin demand. This implies an interactive effect between insulin resistance and beta cell function. In support of such an effect it was recently shown that the summed effects of the risk alleles in TCF7L2, CDKAL1, HHEX; SLC30A8, IGF2BP2, CDKN2A/B, JAZF1 and WFS1 had a stronger effect on beta cell function in participants with low insulin sensitivity than in participants with high insulin sensitivity [39]. Because we found that the genetic variation in beta cell function is partly independent of the genetic variation in ISI, the interactive effect between insulin resistance and beta cell function could be partly due to gene-gene interaction. Failing to account for such genegene interactions may explain some of the missing heritability plaguing GWA studies in diabetes [40].

In the near future, new candidate genes can be expected to derive from the ongoing collaborative GWA studies on diabetes or fasting glucose, which are still growing in scale. We assert that functional annotation of these genes should employ rigorous beta cell function tests including the hyperglycaemic clamp procedure used here. For instance, Schafer et al. [37], using a comparable hyperglycaemic clamp+GLP-1+arginine as used in the current study, showed that carriers of the risk allele in two variants (rs7903146, rs12255372) of the TCF7L2 gene had unchanged GLP-1 secretion, but significantly reduced GLP-1induced insulin secretion. This finding narrows the possible role for TCF7L2 in type 2 diabetes, an often replicated association, to a functional defect in GLP-1 in the beta cells.

The major strength of our study, the clamp-based measurement of insulin sensitivity and insulin responses under a strict and uniform protocol, comes with a major limitation. Due to the expensive, time-consuming and demanding protocols, the sample was relatively small. This is reflected in the fairly broad confidence intervals around the estimates in Tables 2, 3, 4 and 5. As a consequence of the modest sample size, the a priori power to detect common environmental effects, for instance shared dietary practices in childhood, or genetic non-additivity (dominance, epistasis) was very poor [26]. Also, the two-factor structure now found for beta cell responses might prove more complex, i.e. with GLP1-specific and argininespecific genetic factors, when larger samples are assessed. Further caution is needed in generalising these data beyond the sample of relatively young, healthy Europeans used here.

In conclusion, genetic factors explain most of the individual differences in insulin response after administration of glucose and glucose combined with GLP-1 or GLP-1 + arginine in healthy adults. Our results show that the often used first-phase response may give an incomplete picture of the genes that are specific to beta cell function. They also show that the genetic factors influencing beta cell function are partly independent of the factors that influence BMI and ISI, and that in genetic designs 'correction' for BMI and ISI may not always be desirable. To chart the biological effects of (new) candidate genes from GWA studies on type 2 diabetes, the hyperglycaemic GLP-1/arginine challenge test may be a powerful tool.

Acknowledgements The study was financially supported by the Dutch Diabetes Research Foundation (DFN 2002-00-001) and the Dutch organisation for Scientific Research (NWO-MaGW 480-04-004). We thank all participants for being so kind as to take part in this study.

Duality of interest The authors declare that there is no duality of interest associated with this manuscript.

\section{References}

1. No authors listed (2003) Report of the Expert Committee on the Diagnosis and Classification of Diabetes Mellitus. Diabetes Care 26(Suppl 1):S5-S20

2. Newman B, Selby JV, King MC, Slemenda C, Fabsitz R, Friedman GD (1987) Concordance for type 2 (non-insulin-dependent) diabetes mellitus in male twins. Diabetologia 30:763-768

3. Kaprio J, Tuomilehto J, Koskenvuo M et al (1992) Concordance for type 1 (insulin-dependent) and type 2 (non-insulin-dependent) diabetes mellitus in a population-based cohort of twins in Finland. Diabetologia 35:1060-1067 
4. Medici F, Hawa M, Ianari A, Pyke DA, Leslie RD (1999) Concordance rate for type II diabetes mellitus in monozygotic twins: actuarial analysis. Diabetologia 42:146-150

5. Beck-Nielsen H, Vaag A, Poulsen P, Gaster M (2003) Metabolic and genetic influence on glucose metabolism in type 2 diabetic subjects - experiences from relatives and twin studies. Best Pract Res Clin Endocrinol Metab 17:445-467

6. Watanabe RM, Valle T, Hauser ER et al (1999) Familiality of quantitative metabolic traits in Finnish families with non-insulindependent diabetes mellitus. Finland-United States Investigation of NIDDM Genetics (FUSION) Study investigators. Hum Hered 49:159-168

7. Hsueh WC, Mitchell BD, Aburomia R et al (2000) Diabetes in the Old Order Amish: characterization and heritability analysis of the Amish Family Diabetes Study. Diabetes Care 23:595-601

8. Meigs JB, Cupples LA, Wilson PW (2000) Parental transmission of type 2 diabetes: the Framingham Offspring Study. Diabetes 49:2201-2207

9. Hanson RL, Imperatore G, Narayan KM et al (2001) Family and genetic studies of indices of insulin sensitivity and insulin secretion in Pima Indians. Diabetes Metab Res Rev 17:296-303

10. Mills GW, Avery PJ, McCarthy MI et al (2004) Heritability estimates for beta cell function and features of the insulin resistance syndrome in UK families with an increased susceptibility to type 2 diabetes. Diabetologia 47:732-738

11. Lehtovirta M, Kaprio J, Forsblom C, Eriksson J, Tuomilehto J, Groop L (2000) Insulin sensitivity and insulin secretion in monozygotic and dizygotic twins. Diabetologia 43:285-293

12. Poulsen P, Levin K, Petersen I, Christensen K, Beck-Nielsen H, Vaag A (2005) Heritability of insulin secretion, peripheral and hepatic insulin action, and intracellular glucose partitioning in young and old Danish twins. Diabetes 54:275-283

13. Frayling TM (2007) Genome-wide association studies provide new insights into type 2 diabetes aetiology. Nat Rev Genet 8:657-662

14. Florez JC (2008) Newly identified loci highlight beta cell dysfunction as a key cause of type 2 diabetes: where are the insulin resistance genes? Diabetologia 51:1100-1110

15. Elbein SC, Hasstedt SJ, Wegner K, Kahn SE (1999) Heritability of pancreatic beta-cell function among nondiabetic members of Caucasian familial type 2 diabetic kindreds. J Clin Endocrinol Metab 84:1398-1403

16. Hong Y, Weisnagel SJ, Rice T et al (2001) Familial resemblance for glucose and insulin metabolism indices derived from an intravenous glucose tolerance test in Blacks and Whites of the HERITAGE Family Study. Clin Genet 60:22-30

17. Lehtovirta M, Kaprio J, Groop L, Trombetta M, Bonadonna RC (2005) Heritability of model-derived parameters of beta cell secretion during intravenous and oral glucose tolerance tests: a study of twins. Diabetologia 48:1604-1613

18. Gautier JF, Fetita S, Sobngwi E, Salaun-Martin C (2005) Biological actions of the incretins GIP and GLP-1 and therapeutic perspectives in patients with type 2 diabetes. Diabetes Metab $31: 233-242$

19. Brandle M, Lehmann R, Maly FE, Schmid C, Spinas GA (2001) Diminished insulin secretory response to glucose but normal insulin and glucagon secretory responses to arginine in a family with maternally inherited diabetes and deafness caused by mitochondrial tRNA(LEU(UUR)) gene mutation. Diabetes Care 24:1253-1258

20. Stumvoll M, Fritsche A, Haring HU (2002) Clinical characterization of insulin secretion as the basis for genetic analyses. Diabetes 51(Suppl 1):S122-S129
21. Fritsche A, Stefan N, Hardt E, Schutzenauer S, Haring H, Stumvoll M (2000) A novel hyperglycaemic clamp for characterization of islet function in humans: assessment of three different secretagogues, maximal insulin response and reproducibility. Eur J Clin Invest 30:411-418

22. Gerich JE (2002) Is reduced first-phase insulin release the earliest detectable abnormality in individuals destined to develop type 2 diabetes? Diabetes 51(Suppl 1):S117-S121

23. Ahren B, Pacini G (2004) Importance of quantifying insulin secretion in relation to insulin sensitivity to accurately assess beta cell function in clinical studies. Eur J Endocrinol 150:97104

24. Boomsma DI, de Geus EJC, Vink JM et al (2006) Netherlands Twin Register: from twins to twin families. Twin Res Hum Genet 9:849-857

25. Simonis-Bik AM, Eekhoff EM, Diamant M et al (2008) The heritability of HbA1c and fasting blood glucose in different measurement settings. Twin Res Hum Genet 11:597-602

26. Posthuma D, Boomsma DI (2000) A note on the statistical power in extended twin designs. Behav Genet 30:147-158

27. DeFronzo RA, Tobin JD, Andres R (1979) Glucose clamp technique: a method for quantifying insulin secretion and resistance. Am J Physiol 237:E214-E223

28. Snijder MB, Dekker JM, Visser M et al (2003) Associations of hip and thigh circumferences independent of waist circumference with the incidence of type 2 diabetes: the Hoorn Study. Am J Clin Nutr 77:1192-1197

29. Astles JR, Sedor FA, Toffaletti JG (1996) Evaluation of the YSI 2300 glucose analyzer: algorithm-corrected results are accurate and specific. Clin Biochem 29:27-31

30. Neale MC, Boker SM, Xie G, Maes HH (2006) Mx: Statistical modeling, 7th edn. Virginia Commonwealth University Department of Psychiatry, Richmond

31. Neale MC, Cardon LR (1992) Methodology for genetic studies of twins and families. Kluwer, Dordrecht

32. Huxley R, James WPT, Barzi F et al (2008) Ethnic comparisons of the cross-sectional relationships between measures of body size with diabetes and hypertension. Obes Rev 9(Suppl 1):53-61

33. Maes HH, Neale MC, Eaves LJ (1997) Genetic and environmental factors in relative body weight and human adiposity. Behav Genet 27:325-351

34. Frayling TM, Timpson NJ, Weedon MN et al (2007) A common variant in the FTO gene is associated with body mass index and predisposes to childhood and adult obesity. Science 316:889-894

35. Prokopenko I, McCarthy MI, Lindgren CM (2008) Type 2 diabetes: new genes, new understanding. Trends Genet 24:613-621

36. Groenewoud MJ, Dekker JM, Fritsche A et al (2008) Variants of CDKAL1 and IGF2BP2 affect first-phase insulin secretion during hyperglycaemic clamps. Diabetologia 51:1659-1663

37. Schafer SA, Tschritter O, Machicao F et al (2007) Impaired glucagon-like peptide-1-induced insulin secretion in carriers of transcription factor 7-like 2 (TCF7L2) gene polymorphisms. Diabetologia 50:2443-2450

38. Schafer SA, Mussig K, Staiger H et al (2009) A common genetic variant in WFS1 determines impaired glucagon-like peptide-1induced insulin secretion. Diabetologia 52:1075-1082

39. Haupt A, Guthoff M, Schafer SA et al (2009) The inhibitory association of recent type 2 diabetes risk loci on insulin secretion is modulated by insulin sensitivity. J Clin Endocrinol Metab 94:1775-1780

40. McCarthy MI, Zeggini E (2009) Genome-wide association studies in type 2 diabetes. Curr Diab Rep 9:164-171 